\title{
BMJ Open Preventing type 2 diabetes among Palestinians: comparing five future policy scenarios
}

\author{
Niveen M E Abu-Rmeileh, ${ }^{1}$ Abdullatif Husseini, ${ }^{1,2}$ Simon Capewell, ${ }^{3}$ \\ Martin O'Flaherty, ${ }^{3}$ on behalf of MEDCHAMPS project
}

To cite: Abu-Rmeileh NME, Husseini A, Capewell S, et al. Preventing type 2 diabetes among Palestinians: comparing five future policy scenarios. BMJ Open 2014;3: e003558. doi:10.1136/ bmjopen-2013-003558

- Prepublication history and additional material for this paper is available online. To view these files please visit the journal online (http://dx.doi.org/10.1136/ bmjopen-2013-003558).

Received 10 July 2013 Revised 30 October 2013 Accepted 11 November 2013

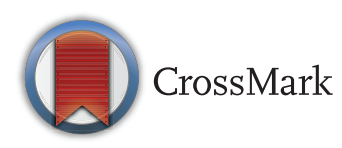

For numbered affiliations see end of article.

Correspondence to Dr Niveen M E Abu-Rmeileh; nrmeileh@birzeit.edu

\section{ABSTRACT}

Objective: This paper aims to provide estimates of future diabetes prevalence in the West Bank, occupied Palestinian territory (oPt), and to compare five future policy scenarios for diabetes prevention.

Design: We created and refined a mathematical Markov model that integrates population, obesity and smoking trends to estimate future diabetes prevalence. Model parameters were derived from the literature. Diabetes incidence was estimated using DISMOD software. We developed the model for the Palestinian population based on data available for the period 2000-2010, and validated the model by comparing predicted diabetes prevalence to subsequent actual observed diabetes prevalence rates.

Setting: West Bank oPt.

Results: Palestinian diabetes mellitus prevalence estimated by the model (for adults aged 25 or more) was $9.7 \%$ in 2000 , increasing to $15.3 \%$ by 2010 . Prevalence in men increased from $9.1 \%$ to $16.9 \%$ and in women from $10.2 \%$ to $13.6 \%$. Comparisons of the model results with the observed prevalence in the Palestinian Family Health Survey showed a close fit. The model forecasts were $20.8 \%$ for 2020 and $23.4 \%$ for 2030. A $2.8 \%$ reduction in diabetes prevalence could be achieved if obesity trends start to decline by $5 \%$ in a 5 -year period. If obesity prevalence was reduced by $35 \%$ in 10 years, as suggested by the WHO, diabetes prevalence might be decreased by $20 \%$. Conclusions: The model estimates an increase in the prevalence of diabetes which poses a large challenge to the health system. However, if bold but reasonable action is taken, effective interventions could reduce diabetes prevalence and hence the number of patients with diabetes.

\section{INTRODUCTION}

The International Diabetes Federation (IDF) suggested that there will be approximately 365 million people with diabetes worldwide in 2011. The MENA (Middle East and North Africa) region will have the highest prevalence of diabetes $(12.5 \%)$ and the second largest proportional increase in the number of

\section{Strength and limitations in this study}

- The model may be appropriate for most lowincome and middle-income countries because it is simple, does not require sophisticated statistical software nor huge amounts of specific data.

- Not all relevant risk factors, such as physical inactivity, were included in the current model. Body mass index was used as a measure of obesity and finally the limited data available to estimate obesity trends for the Palestinian population.

- The model can provide estimates for future diabetes prevalence which can inform policy using different intervention scenarios that can target the specific risk factors.

people with diabetes (85 million). ${ }^{1}$ However, this predicted increase was mainly based on demographic changes and the assumption that urbanisation is a satisfactory proxy for risk factors such as obesity, smoking and physical activity. $^{2}$

In Palestine, a few epidemiological studies have focused on non-communicable diseases including diabetes. ${ }^{3}$ Most studies were crosssectional in nature and provided estimates of the current prevalence for diabetes and obesity. However, the estimates of future prevalence which are urgently needed for proper planning are not available. Furthermore, the estimates reported by the IDF and the Global Burden of Disease study are broad and do not apply specifically to the Palestinian context. ${ }^{1}{ }^{2}$ Thus, this paper aims to provide estimates of future diabetes prevalence in the West Bank, occupied Palestinian territory $(\mathrm{oPt})$, and offer a modelling platform for policy decision-making.

\section{METHODS}

The model integrates information on population, obesity and smoking trends at a given point of time to estimate diabetes prevalence in the future using a Markov model. The 
model is implemented in MS Excel and can accommodate different diabetes definitions.

We assume that the population can be divided into several pools: diabetes mellitus, obese, smoker and 'healthy' (eg, non-obese, non-smokers and people without diabetes). A proportion of the population in each pool moves through pathways to other states.

Population demographic trends are used to inform the relative size of the 'starting states', and transition probabilities are used to estimate the proportion of persons moving from the starting states to the diabetes and death states. There are two 'absorbing states': diabetes mellitus (DM)-related death and non-DM-related deaths. In this way, mortality competing risks are modelled. Potential overlaps between the healthy, obese and smoking groups are managed by calculating the conditional probabilities of membership.

\section{Data needed}

The model requires data by 10-year age and gender bands, starting at 25, ending 75+. Data needed for the initial year include population size and age distribution, diabetes prevalence, obesity prevalence, smoking prevalence and total mortality. Data needed for subsequent years for forecasting purposes include population projections, obesity and smoking trends. Data needed for incidence calculation include diabetes prevalence, total mortality and casefatality. The sources of data used for trend and validation are listed in table 1. The Palestinian Demographic and Health Surveys and Ministry of Health Information Centre were the main sources of data used. The use of these secondary data was not needed.

Diabetes incidence and specific mortality were estimated using the methods developed by Barendregt et al. ${ }^{4}$ The methods for diabetes incidence and specific mortality are described in the technical appendix. Diabetes incidence, case-fatality and mortality stratified by age and sex were

\begin{tabular}{|c|c|c|c|c|}
\hline 2000 & Population & $\begin{array}{l}\text { Diabetes } \\
\text { prevalence }\end{array}$ & $\begin{array}{l}\text { Obesity } \\
\text { prevalence }\end{array}$ & $\begin{array}{l}\text { Smoking } \\
\text { prevalence }\end{array}$ \\
\hline \multicolumn{5}{|c|}{ Men (n=336 965) } \\
\hline $25-34$ & +138888 & 0.0133 & 0.159 & 0.594 \\
\hline $35-44$ & 92050 & 0.0871 & 0.195 & 0.561 \\
\hline $45-54$ & 46207 & 0.1516 & 0.353 & 0.525 \\
\hline $55-64$ & 28582 & 0.2451 & 0.324 & 0.422 \\
\hline $65-74$ & 19508 & 0.2467 & 0.298 & 0.331 \\
\hline $75+$ & 11730 & 0.1774 & 0.268 & 0.331 \\
\hline \multicolumn{5}{|c|}{ Women $(n=343260)$} \\
\hline $25-34$ & +133095 & 0.0052 & 0.213 & 0.041 \\
\hline $35-44$ & 86979 & 0.0386 & 0.401 & 0.071 \\
\hline $45-54$ & 47457 & 0.1522 & 0.564 & 0.064 \\
\hline $55-64$ & 36124 & 0.2833 & 0.602 & 0.054 \\
\hline $65-74$ & 25670 & 0.3294 & 0.432 & 0.033 \\
\hline $75+$ & 13935 & 0.3696 & 0.354 & 0.033 \\
\hline
\end{tabular}

calculated using DISMOD programme based on three inputs with the assumption that these parameters are constant over time. However, this was taken into account when calculating the incidence parameter using trends in DISMOD: first diabetes prevalence for the year 2004 obtained from the Palestinian Demographic Health Survey, diabetes mellitus remission rate which was assumed 0 and diabetes mellitus relative risk (RR) for mortality which was estimated as proposed by Barendregt $e t a l,{ }^{4}$ and based on the usual RR for mortality. The formula is

$$
\mathrm{RR}_{\mathrm{ADJ}}=\frac{\mathrm{RR}}{\mathrm{pRR}+1-\mathrm{p}}
$$

\section{Model validation}

Model validation is an important aspect of any modelling exercise, frequently overlooked.

We developed a model for the West Bank, oPt, over the period 2000-2020. During that period, subsequent surveys were conducted in DHS 2004, PFHS 2006, PFHS 2010, Stepwise Survey 2010 and we compared the model outputs with the observed prevalence estimates.

\section{Sensitivity analysis}

We used the analysis of the extremes method (Briggs), consisting of running the model with all parameters set to a minimum and maximum realistic values. This is a very conservative approach, but allows a more transparent understanding of the weight of each parameter regarding model outcomes.

\begin{tabular}{|c|c|}
\hline 'What if' policy questions & Reference \\
\hline $\begin{array}{l}\text { Given a } 2010 \text { baseline: What will be } \\
\text { the impact of a } 5 \% \text { relative reduction } \\
\text { in obesity prevalence by } 2015 \text { on } \\
\text { diabetes burden in the West Bank? }\end{array}$ & $\begin{array}{l}\text { Ministry of Health, } \\
\text { Turkey }^{5}\end{array}$ \\
\hline $\begin{array}{l}\text { What will be the impact of a } 5 \% \\
\text { relative reduction in obesity } \\
\text { prevalence by } 2020 \text { on diabetes } \\
\text { burden in the West Bank? }\end{array}$ & Assumption \\
\hline $\begin{array}{l}\text { What will be the impact of a } 10 \% \\
\text { relative reduction in obesity } \\
\text { prevalence by } 2020 \text { on diabetes } \\
\text { burden in the West Bank? }\end{array}$ & Assumption \\
\hline $\begin{array}{l}\text { What will be the impact of halting the } \\
\text { rise in obesity prevalence (15\%) by } \\
2020 \text { on diabetes burden in the West } \\
\text { Bank? }\end{array}$ & $\mathrm{WHO}^{6}$ \\
\hline $\begin{array}{l}\text { What will be the impact of } 35 \% \\
\text { relative reduction in obesity } \\
\text { prevalence by } 2020 \text { (baseline 2010) } \\
\text { on diabetes burden in the West } \\
\text { Bank? }\end{array}$ & WHO-EMRO \\
\hline
\end{tabular}




\section{Policy scenarios}

Since there are no current targets for adult obesity at the national level or for the West Bank, and since obesity is increasing and is predicted to continue to increase, we used a Mediterranean country, Turkey targets (scenario 1), WHO targets (scenario 4) and WHO regional targets (scenario 5). Further we proposed two targets which might be feasible (scenario 2) and ideal (scenario 3). These targets are set for population-based prevention.

\section{RESULTS}

\section{Population characteristics at starting point}

The prevalence of diabetes among the Palestinian population aged 25 and above, living in the West Bank in the year 2000 was $9.1 \%$ for men and $10.2 \%$ for women. The risk factors included in the study were obesity and smoking (table 2). Obesity is a common risk factor among the Palestinian population with $22.1 \%$ prevalence among men and $37.2 \%$ among women. Smoking prevalence was very high among men $(53.7 \%)$ but very low among women (5.2\%).

\section{Risk factor trends 2000-2030}

The changes in obesity and smoking prevalence were assumed to be linear with various degrees between men and women and within different age groups. Obesity prevalence was higher among women compared with men at 2000 with the highest prevalence observed for the ages 45-54 years and 55-64 years. The prevalence reached plateau at the age of 55-64 years and 65-74 years for women and 65-74 years for men. Obesity prevalence increased in men and women while smoking prevalence decreased in the period 2000-2030. The decrease in smoking prevalence varied between the age groups with a faster decrease among the older age groups.

Obesity prevalence has increased from $22.1 \%$ in men and $37.2 \%$ in women in 2000 to $29.1 \%$ in men and $39.6 \%$ women in 2010. Smoking trends decreased over 10 years period. Among men, smoking decreased from 53.7\% in 2000 to $51.3 \%$ in 2004 and $49.4 \%$ in 2010 . Among women, smoking prevalence almost halved between 2000 and 2010.

\section{Diabetes incidence and total mortality}

Diabetes incidence was estimated using DISMOD based on diabetes prevalence, total mortality, case-fatality and remission rate. The estimated incidence for the year 2004 ranged between 0.002 for those aged 25-34 years to 0.041 and 0.026 for men and women aged 55-64 years and 0.026 for men and 0.011 for women older than 65 years.

\section{Model diabetes prevalence estimates}

Palestinian diabetes prevalence estimated by the model (for those aged 25 or more) was $9.7 \%$ in 2000 (95\% CI $7.9 \%$ to $11.6 \%$ ), increasing to $15.3 \%$ (95\% CI $12.3 \%$ to $17.6 \%)$ by 2010 (figure 1). Diabetes prevalence is predicted to increase rapidly between 2010 and 2020 and then the increase starts to slow down. Prevalence in men increased from $9.1 \%(95 \%$ CI $7.3 \%$ to $11.0 \%)$ to $16.9 \%(95 \%$ CI $14.6 \%$ to $19.4 \%$ ) and in women from $10.2 \%$ (95\% CI $8.4 \%$ to $12.3 \%$ ) to $13.6 \%$ (95\% CI $11.3 \%$ to $15.8 \%$ ).

\section{Model validation}

Comparisons of the model estimates with the observed prevalence in the Palestinian Family Health Survey showed a good fit. The observed prevalence was 10.6 versus $11.4 \%$ predicted in 2004, 11.8 versus $12.6 \%$ in 2006 and 13.8 versus $15.3 \%$ predicted using Stepwise survey results.

\section{Diabetes prevalence projections}

The forecasts were $20.6 \%$ (95\% CI $18.5 \%$ to $23.7 \%$ ) for 2020 and $21.5 \%$ (95\% CI $20.7 \%$ to $25.8 \%$ ) for 2030.The estimated number of patients with diabetes is expected thus to reach 215000 in 2015, 289000 in 2020 and 444000 in 2030.

\section{Policy scenarios}

If trends in obesity start to decline by $5 \%$ starting in 2015 , a reduction in diabetes prevalence of $8.3 \%$ could be achieved in 15 years (2030). If obesity declined by $10 \%$ in 10 years as a realistic target, a $5.3 \%$ reduction in diabetes prevalence of $11.1 \%$ might be expected. A more ambitious scenario assuming a $15 \%$ reduction in 10 years to achieve the WHO target might result in a $11.1 \%$. However, achieving the EMRO-WHO target of a $35 \%$ obesity reduction in 10 years could result in $20.2 \%$ reduction in diabetes prevalence (table 2 ).

\section{DISCUSSION}

This paper provides, for the first time, Palestinian-specific future estimates for diabetes prevalence rather than just reporting point prevalence.

The predicted prevalence is worryingly high and is expected to increase by $35 \%$ from 2010 to 2020. This is entirely consistent with reports from the IDF. ${ }^{2}$ The main factor fuelling this increase in diabetes prevalence is the expected continuing increase in obesity prevalence. ${ }^{7}$ The starting point for obesity prevalence among women is relatively high and is higher than in men. However, men are catching up; their increase overtime is much faster than in women. Although in some countries obesity prevalence increases and then reaches plateau, this phenomenon is not observed in the Palestinian population yet. Hence obesity prevalence forecast was based on the past trend with the assumption of continuous increase.

The estimates of diabetes prevalence calculated from the model were comparable with actual diabetes prevalence measured in the period 2000-2010. The estimates of diabetes prevalence reported in this paper are believed to be more realistic compared with the estimates reported by the IDF and the Global prevalence of diabetes estimates which were critiqued for under estimating the prevalence of diabetes, probably as a result of using only demographic 
Table 2 Prevalence of diabetes and the number of people with diabetes estimated for the period 2000 and 2030

\begin{tabular}{|c|c|c|c|c|c|c|c|c|c|c|c|c|c|c|c|c|c|}
\hline \multirow[b]{2}{*}{ Year } & \multirow{2}{*}{\multicolumn{2}{|c|}{$\begin{array}{l}\text { Baseline } \\
\text { Estimated } \\
\text { number }\end{array}$}} & \multicolumn{3}{|c|}{$\begin{array}{l}5 \% \text { Obese reduction } \\
\text { in } 5 \text { years }\end{array}$} & \multicolumn{3}{|c|}{$\begin{array}{l}\text { WHO target to halt } \\
\text { obesity prevalence } \\
\text { ( } 15 \% \text { in } 10 \text { years) }\end{array}$} & \multicolumn{3}{|c|}{$\begin{array}{l}\text { WHO-EMRO } 35 \% \text { obese } \\
\text { reduction in } 10 \text { years }\end{array}$} & \multicolumn{3}{|c|}{$\begin{array}{l}5 \% \text { Obese reduction } \\
\text { in } 10 \text { years }\end{array}$} & \multicolumn{3}{|c|}{$\begin{array}{l}10 \% \text { Obese } \\
\text { reduction } \\
\text { in } 10 \text { years }\end{array}$} \\
\hline & & & $\begin{array}{l}\text { Estimated } \\
\text { number }\end{array}$ & & Number & $\begin{array}{l}\text { Estimated } \\
\text { number }\end{array}$ & & Number & $\begin{array}{l}\text { Estimated } \\
\text { number }\end{array}$ & & Number & $\begin{array}{l}\text { Estimated } \\
\text { number }\end{array}$ & & Number & $\begin{array}{l}\text { Estimated } \\
\text { number }\end{array}$ & & Number \\
\hline 2015 & 215042 & & 211219 & & 3823 & 210278 & & 4764 & 206673 & & 8369 & 212176 & & 2866 & 211219 & & 3823 \\
\hline Min-Max & 148627 & 292814 & 146443 & 286159 & & 146443 & 286159 & & 146443 & 286159 & & 146443 & 146443 & & 146443 & 286159 & \\
\hline 2020 & 289103 & & 277317 & & 11786 & 273902 & & 15201 & 261510 & & 27593 & 280866 & & 8236 & 277317 & & 11786 \\
\hline Min-Max & 207052 & 398856 & 198010 & 372107 & & 198010 & 372107 & & 198010 & 372107 & & 198010 & 198010 & & 198010 & 372107 & \\
\hline 2025 & 365597 & & 342837 & & 22760 & 335582 & & 30015 & 310687 & & 54910 & 350552 & & 15045 & 342837 & & 22760 \\
\hline Min-Max & 272271 & 515599 & 251930 & 456947 & & 251930 & 456947 & & 251930 & 456947 & & 251930 & 251930 & & 251930 & 456947 & \\
\hline 2030 & 444296 & & 407308 & & 36988 & 394879 & & 49416 & 354622 & & 89674 & 420837 & & 23458 & 407308 & & 36988 \\
\hline \multirow[t]{2}{*}{ Min-Max } & 342629 & 641053 & 307266 & 541257 & & 307266 & 541257 & & 307266 & 541257 & & 307266 & 307266 & & 307266 & 541257 & \\
\hline & \multicolumn{2}{|c|}{$\begin{array}{l}\text { Estimated } \\
\text { prevalence }\end{array}$} & \multicolumn{2}{|c|}{$\begin{array}{l}\text { Estimated } \\
\text { prevalence }\end{array}$} & $\begin{array}{l}\text { Per centage } \\
\text { of reduction }\end{array}$ & \multicolumn{2}{|c|}{$\begin{array}{l}\text { Estimated } \\
\text { prevalence }\end{array}$} & $\begin{array}{l}\text { Per centage } \\
\text { of reduction }\end{array}$ & \multicolumn{2}{|c|}{$\begin{array}{l}\text { Estimated } \\
\text { prevalence }\end{array}$} & $\begin{array}{l}\text { Per centage } \\
\text { of reduction }\end{array}$ & \multicolumn{2}{|c|}{$\begin{array}{l}\text { Estimated } \\
\text { Prevalence }\end{array}$} & $\begin{array}{l}\text { Per centage } \\
\text { of reduction }\end{array}$ & \multicolumn{2}{|c|}{$\begin{array}{l}\text { Estimated } \\
\text { Prevalence }\end{array}$} & $\begin{array}{l}\text { Per } \\
\text { centage of } \\
\text { reduction }\end{array}$ \\
\hline 2015 & 18.4 & & 18.1 & & 1.8 & 18.0 & & 2.2 & 17.7 & & 3.9 & 18.2 & & 1.3 & 18.1 & & 1.8 \\
\hline Min-Max & 15.9 & 20.9 & 15.7 & 20.5 & & 15.7 & 20.5 & & $15.7 \%$ & 20.5 & & 15.7 & 20.5 & & 15.7 & 20.5 & \\
\hline 2020 & 20.6 & & 19.8 & & 4.1 & 19.6 & & 5.3 & 18.7 & & 9.5 & 20.1 & & 2.8 & 19.8 & & 4.1 \\
\hline Min-Max & 18.5 & 23.7 & 17.7 & 22.1 & & 17.7 & 22.1 & & 17.7 & 22.1 & & 17.7 & 22.1 & & 17.7 & 22.1 & \\
\hline 2025 & 21.6 & & 20.2 & & 6.2 & 19.8 & & 8.2 & 18.3 & & 15.0 & 20.7 & & 4.1 & 20.2 & & 6.2 \\
\hline Min-Max & 20.1 & 25.3 & 18.6 & 22.5 & & 18.6 & 22.5 & & 18.6 & 22.5 & & 18.6 & 22.5 & & 18.6 & 22.5 & \\
\hline 2030 & 21.5 & & 19.7 & & 8.3 & 19.1 & & 11.1 & 17.1 & & 20.2 & 20.3 & & 5.3 & 19.7 & & 8.3 \\
\hline Min-Max & 20.7 & 25.8 & 18.5 & 21.8 & & 18.5 & 21.8 & 2.2 & 18.5 & 21.8 & & 18.5 & 21.8 & & 18.5 & 21.8 & \\
\hline
\end{tabular}




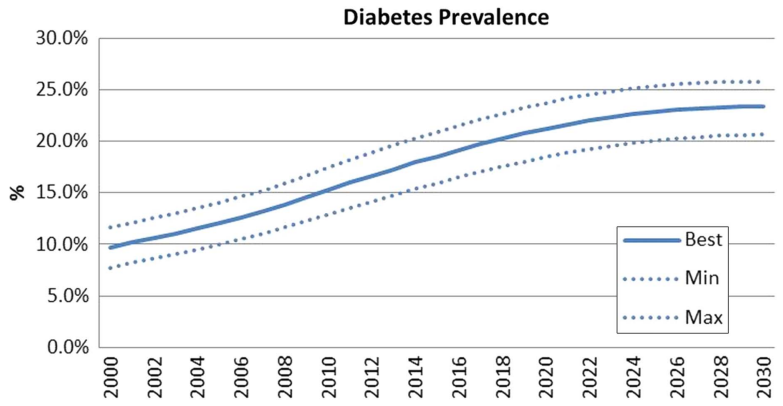

Figure 1 Diabetes prevalence forecasting between 2000 and 2030.

trends and urbanisation as a proxy for diabetes future incidence. ${ }^{2}{ }^{8}$ By contrast, our model used country-specific trends for diabetes risk factors including obesity and smoking in addition to the demographic trends, whereas the Global Burden of Disease (GBD) used urbanisation as a crude proxy measure for obesity and physical inactivity. ${ }^{2}$ The estimates of the model and observed diabetes prevalence reported in national surveys were comparable.

We suggest that this model may be appropriate for most low-income and middle-income countries because it is simple, does not require sophisticated statistical software nor huge amounts of specific data. Furthermore, the model can provide estimates for future diabetes prevalence, which can inform policy using different intervention scenarios that can target the specific risk factors included in the model. Several estimates and projections for global or national diabetes prevalence studies are available.

This newly developed model has some limitations. First, models are simplifications of reality, and not all relevant risk factors, such as physical inactivity, were included in the current model. Reliable physical activity level measurements are difficult to obtain in most low-income and middle-income countries. However, the independent contribution of physical inactivity to diabetes incidence is low, suggesting that the impact of policies increasing physical activity levels in any case is likely to be modest. Second, BMI is an imperfect measure of obesity, visceral obesity (WHR) would be preferable, but its availability might not be as widespread as height and weight measurements. Third, limited data were available to estimate obesity trends for the Palestinian population. Having data on obesity for more than two points in time would improve the estimates for obesity trends. The model also assumes a constant incidence rate and case-fatality rates for the projections. These assumptions make the model estimates more conservative, as both will tend to underestimate the size of the prevalence pool. Despite these limitations, the model predictive ability, as compared with observed, independent estimates of diabetes prevalence seems to be good.

\section{Policy scenarios and their importance}

The paper discusses five population-based intervention policy options and assesses their impact on future diabetes prevalence. Since obesity prevalence is increasing and is predicted to continue to increase, we selected populationbased interventions targeting obesity. The Palestinians have a national strategy for preventing the non-communicable diseases. However, this strategy did not set a target for obesity reduction, hence we used WHO, global and regional targets (EMRO), plus two additional targets, one feasible and one ideal. The ambitious targets set by the WHO (a 35\% decrease in obesity) would achieve the highest reduction in diabetes prevalence, but might not be feasible. Setting a lower target initially followed by a higher target for longer term might be more realistic. The implementation of the proposed intervention needs to be investigated thoroughly.

\section{Public health implications}

The people in Palestine and the Middle East face an increasing prevalence of diabetes. Immediate action is needed to halt this public health disaster. Diabetes can be prevented mainly by policy interventions focusing on obesity reduction. A reduction in calorie intake was reinforced by increased physical activity. ${ }^{9-11}$ The American Heart Association Council on Epidemiology and Prevention provided an ecological framework for obesity prevention that emphasised the importance of the social, environmental and political context and their powerful influence on the behaviour of families and individuals. ${ }^{12}$

Finally, this model has provided reasonably close estimates of diabetes prevalence for oPt over the 2000-2010 period, compared with values observed in contemporary independent surveys in the same population. The model also estimates a worrying increase in the future prevalence of diabetes and this will cause huge economic and healthcare problems.

However, if bold action is now taken, a substantial reduction in the diabetes prevalence and consequently the number of patients with diabetes could still be achieved.

\section{Author affiliations}

${ }^{1}$ Institute of Community and Public Health, Birzeit University, Ramallah, Palestinian Territory Occupied

${ }^{2}$ Public Health Program, Department of Health Sciences, Qatar University, Doha, Qatar

${ }^{3}$ Department of Public Health and Policy, University of Liverpool, Liverpool, UK

Contributors NMEAR and MOF were responsible for adapting the diabetes model to the Palestinian context. NMEAR drafted the article. MOF, SC and AH contributed to the writing and finalisation of the manuscript. NA-R is the guarantor.

Funding The European Community's Seventh Framework Programme (grant number FP7-HEALTH-2007-B. Project number 223075).

\section{Competing interests None.}

Ethics approval The Central Birzeit University's ethics committee has set out the rules for ethical conduct which we abide by very closely. Those entail maintaining confidentiality (and full disclosure to participants of the study and its importance), informed consent, maintaining the dignity of participants and doing no harm. Birzeit University wide rules stipulate in item 5 under General Guidelines that "Research entailing the use and/or analysis of already collected data, such as, for example, the Palestinian Central Bureau of Statistics data sets and other such data which was collected by various institutions and researchers; or research entailing reading texts and analysing for content, do not need ethics 
reviews". As such, ethical review for this study was waived, given that the data was collected by others and did not reveal the identity of participants in any way.

Provenance and peer review Not commissioned; externally peer reviewed.

Data sharing statement No additional data are available.

Open Access This is an Open Access article distributed in accordance with the Creative Commons Attribution Non Commercial (CC BY-NC 3.0) license which permits others to distribute, remix, adapt, build upon this work noncommercially, and license their derivative works on different terms, provided the original work is properly cited and the use is non-commercial. See: http:// creativecommons.org/licenses/by-nc/3.0/

\section{REFERENCES}

1. Whiting DR, Guariguata L, Weil C, et al. IDF diabetes atlas: global estimates of the prevalence of diabetes for 2011 and 2030. Diabetes Res Clin Pract 2011;94:311-21.

2. Wild S, Roglic G, Green A, et al. Global prevalence of diabetes: estimates for the year 2000 and projections for 2030. Diabetes Care 2004:27:1047-53.

3. Husseini A, Abu-Rmeileh N, Mikki N, et al. Cardiovascular diseases, diabetes mellitus, and cancer in the occupied Palestinian territory. Lancet 2009;373:1041-9.

4. Barendregt J, Baan C, Bonneux L. An indirect estimate of the incidence of non-insulin-dependent diabetes mellitus. Epidemiology 2000;11:274-9.
5. Ministry of Health of Turkey-General Directorate of Primary Health Care. Obesity prevention and control program of Turkey 2010-2014. Ankara, Turkey, 2010.

6. WHO. Targets to monitor progress in reducing the burden of noncommunicable diseases [database on the Internet] 2011 [cited Jan 2013].

7. Kelly T, Yang W, Chen C-S, et al. Global burden of obesity in 2005 and projections to 2030. Int J Obes 2008;32:1431-7.

8. Guariguata L, Whiting D, Weil C, et al. The International Diabetes Federation diabetes atlas methodology for estimating global and national prevalence of diabetes in adults. Diabetes Res Clin Pract 2011;94(3):322-32.

9. Morenga LT, Mallard S, Mann J. Dietary sugars and body weight: systematic review and meta-analyses of randomised controlled trials and cohort studies. BMJ 2013;346:f1240.

10. Ahmad LA, Crandall JP. Type 2 diabetes prevention: a review. Clin Diabetes 2010;28:53-9.

11. Basu S, Yoffe P, Hills N, et al. The relationship of sugar to population-level diabetes prevalence: an econometric analysis of repeated cross-sectional data. PLOS ONE 8:e57873.

12. Kumanyika SK, Obarzanek E, Stettler N, et al. Population-based prevention of obesity: the need for comprehensive promotion of healthful eating, physical activity, and energy balance: a scientific statement from American Heart Association Council on Epidemiology and Prevention, Interdisciplinary Committee for prevention (formerly the expert panel on population and prevention science). Circulation 2008;118:428-64. 